Bio-grafía. Escritos sobre la Biología y su Enseñanza. ISSN 2027-1034

Número Extraordinario. p.p. 317-325

Memorias del Primer encuentro ambiental Universidad, ambiente y sustentabilidad: experiencias y prácticas.

\title{
TALLER: PRÁCTICAS DE LABORATORIO SUSTENTABLES; UN DIÁLOGO DESDE EL CUIDADO DEL AMBIENTE Y LA ENSEÑANZA DE LA FÍSICA. UNA PROPUESTA DESDE LAS MÁQUINAS DE GOLDBERG
}

Autores: Albornoz Villalobos Paola Andrea, Berdugo Lombana Karen Tatiana, Camargo Castro German David, Casadiegos Fonseca Nidia Raque, Cortes Hernández Carlos German, Cruz Amaya Sonia Stefanny, Cuaran Ordoñez Felipe Arnoldo, Delgado Quintero Edwin Alexander, Díaz Piraquive José Leonardo, Flórez Tovar Jhonny, González Gacheta Andrés Felipe, Gordillo Chaparro Leonel Alexis, Hernández Cepeda Nohora Alejandra, Herrera Acero Ronald Alexander, Jiménez Cárdenas Diego Javier, Mancipe Peña Jorge Jonathan, Moreno Arias Cristian Camilo, Moscoso Riaño Cristian Antonio, Ojeda Acosta Diego Fernando, Páez Pedraza Julián Andrés, Palacio Rangel Jhayson León, Ramírez Méndez Cristian Camilo, Rodríguez Villamil Jean Paul, Salinas Cardona Dora Liceth, Sierra Riaño Natalia Ivonne, Tovar Quimbayo Stefania, Uribe García María Mónica, Villamil Beltrán Natalia, Villamil Turga Alejandro. ${ }^{1}$

Camilo Martínez ${ }^{2}$

\section{Resumen}

Este taller pretende mostrar la importancia de las máquinas de Goldberg como herramienta de dialogo entre las tensiones en la enseñanza de la Física y el problema generalizado de desperdicio de elementos reciclables en las diversas escuelas de básica y media. Que se devele una solución dialógica enmarcada en la creación de prácticas de laboratorio de física, accesible para los estudiantes, entendiendo la accesibilidad a las cuestiones prácticas y por supuesto cognitivas, asociadas a los montajes de laboratorio. Esta propuesta surge de la preocupación generalizada de los estudiantes del seminario de enseñanza de la física, del departamento de Física, apropósito de vislumbrar nuevas formas para la enseñanza de la física en la escuela, que trascienda lo tradicional y se posibiliten como punto de encuentro de las necesidades particulares de la comunidad educativa, para este caso, encontramos dos particularidades de preocupación colectiva, la primera, mostrar la física como una ciencia al alcance de todos y segundo decantar las consecuencias de generar una lógica del cuidado del entorno.

${ }^{1}$ Estudiantes en formación, Licenciatura en Física, Universidad pedagógica Nacional.

${ }^{2}$ Profesor seminario Enseñanza de la Física. Email: camartinezm@ @edagogica.edu.co 
Bio-grafía. Escritos sobre la Biología y su Enseñanza. ISSN 2027-1034

Número Extraordinario. p.p. 317-325

Memorias del Primer encuentro ambiental Universidad, ambiente y sustentabilidad: experiencias y prácticas.

Esta apuesta surge en el marco de las discusiones del seminario de enseñanza de la física (licenciatura en física) a propósito del papel que tiene la física en la escuela frente a su enseñabilidad.

\section{Palabras Claves}

Máquina de Goldberg, Practica de laboratorio, Transversal, cuidado del entorno, enseñan de la física.

\section{Abstrac}

This workshop intends to show the importance of the machines of Goldberg as a tool of dialogue between the tensions in the teaching of the Physics and the generalized problem of waste of recyclable elements in the different schools of basic and average, which owes a dialogic solution in marked in the creation of laboratory practices in physics, accessible to students, understanding accessibility to practical and, of course, cognitive questions associated with laboratory assemblies. This proposal arises from the general concern of the students of the seminary of teaching physics, of the Department of Physics, appropriate to envisage new forms for the teaching of physics in the school, that transcend the traditional and become a meeting point of The particular needs of the educational community, for this case, we find two peculiarities of collective concern, the first, to show physics as a science available to everyone and second to decant the consequences of generating a logic of caring for the environment.

This commitment arises within the framework of the discussions of the seminary teaching physics (degree in physics) regarding the role of physics in the school versus its teaching 
Bio-grafía. Escritos sobre la Biología y su Enseñanza. ISSN 2027-1034

Número Extraordinario. p.p. 317-325

Memorias del Primer encuentro ambiental Universidad, ambiente y sustentabilidad: experiencias y prácticas.

\section{Keywords}

Goldberg Machine, Laboratory Practice, Transverse, Environment Care, Physics Teaching

\section{INTRODUCCIÓN}

Existen diferentes fenómenos sociales, académicos, culturales, etc., que acecen sobre la escuela y por supuesto sobre las prácticas de los sujetos que allí habitan. Pero estas discusiones se han enmarcado en cuestiones particulares que solo les incumben a los expertos de la disciplina, dejando a un lado la interdisciplinariedad, la transversalización y por supuestos las alteridades que allí se pueden percibir. Por ejemplo, uno de estos elementos que ha cuestionado la normalidad de las prácticas en las escuelas, son los procesos de cuidado del entorno y autocuidado, de preocupación total por el área de ciencias naturales y dando como resultados, actividades en el marco del reciclaje, de suprema importancia por supuesto, pero carentes de elementos sistemáticos que garanticen la creación de un ambiente educativo ambiental, matizado por diversas necesidades desde los humano pero también desde lo disciplinar.

Las máquinas de Golberg ${ }^{3}$, son una buena alternativa para la incorporación de las prácticas de reutilización de materiales, la enseñanza y la sustentabilidad, lo cual tiene su justificación. Los montajes del laboratorio de física, en muchas ocasiones son muy sofisticados, costosos y de difícil manejo, lo cual genera apatía por parte de maestros para su utilización, en tanto los costos de estas herramientas son muy elevadas y conseguir alguna pieza es todo un dolor de cabeza. La apuesta de los laboratorios sustentables, es posibilitar una herramienta experimental que no requiera de procesos engorrosos, ni mucho menos de materiales costosos, pero, sobre

${ }^{3}$ Una máquina de Rube Goldberg es un aparato excesivamente safisticado que realiza una tarea muy simple de una manera deliberadamente muy indirecta y elaborada, normalmente hacienda usa de una reacción en cadena. 
Bio-grafía. Escritos sobre la Biología y su Enseñanza. ISSN 2027-1034

Número Extraordinario. p.p. 317-325

Memorias del Primer encuentro ambiental Universidad, ambiente y sustentabilidad: experiencias y prácticas.

todo, montajes de laboratorios que permitan la utilización de diversos materiales en la inmediatez de la necesidad.

OBJETIVO: Aproximar a los asistentes a la fenomenología de la Física (Cinemática, Dinámica termodinámica y electromagnetismo), por medio de montajes de laboratorio sustentables desde la mirada de las máquinas de Goldberg.

Duración (60 minutos por taller).

Se propone un tiempo de 60 minutos para que los asistentes puedan participar de los cuatro montajes de laboratorio, es decir un promedio de 15 minutos por práctica. Sin plantear, por supuesto, obligatoriedad en la participación de los cuatro montajes.

\section{MATERIALES}

A continuación, se listan los materiales por máquina y eje temático, teniendo como elemento de relación, la reutilización de materiales reciclables y renombre de estos a tecnicismos de los montajes de laboratorio de la física.

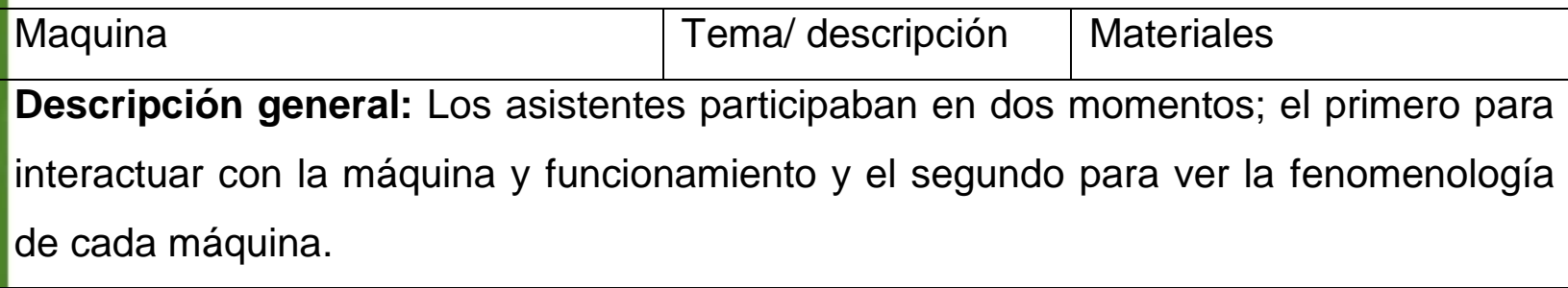


Bio-grafía. Escritos sobre la Biología y su Enseñanza. ISSN 2027-1034

Número Extraordinario. p.p. 317-325

Memorias del Primer encuentro ambiental Universidad, ambiente y sustentabilidad: experiencias y prácticas.

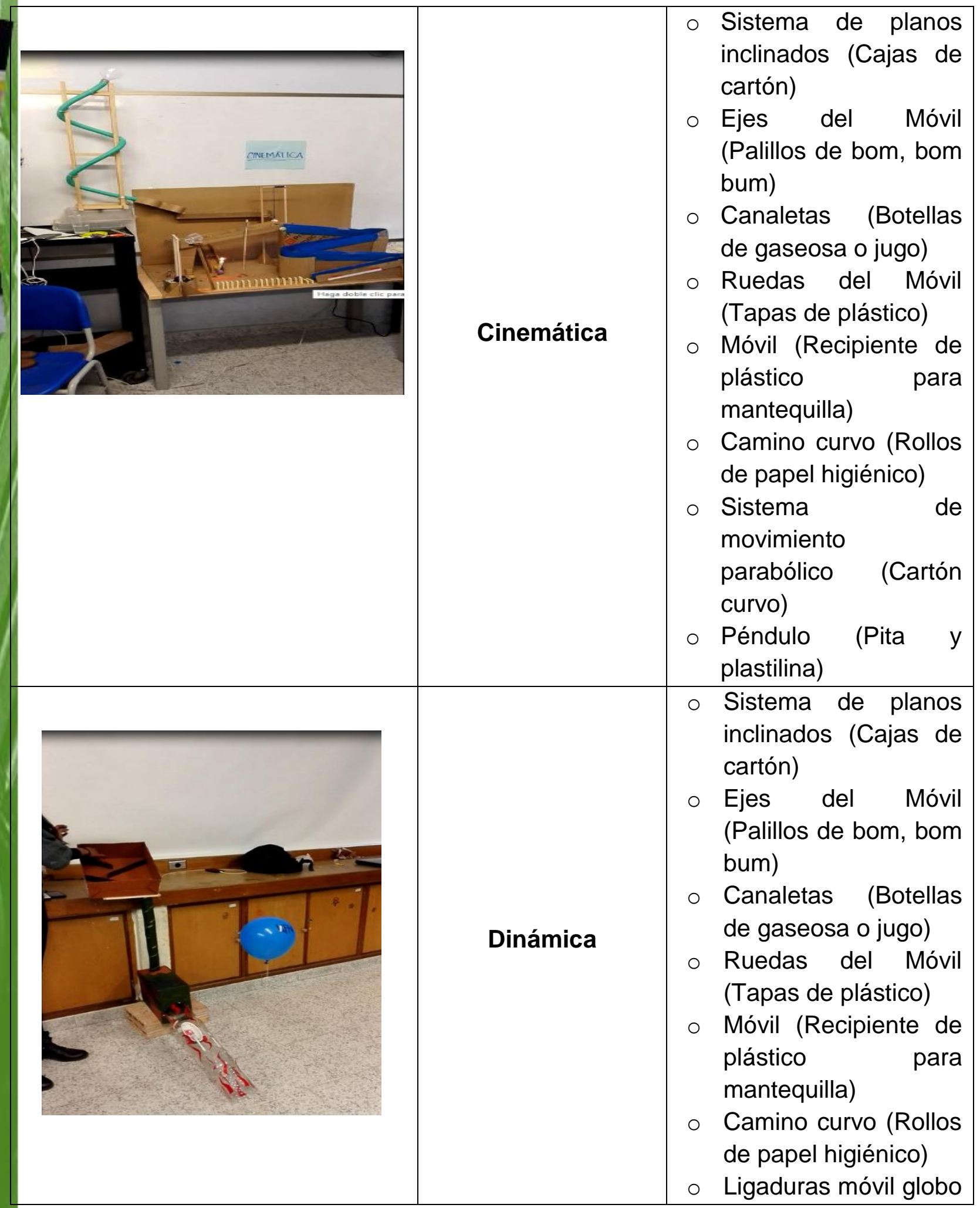


Bio-grafía. Escritos sobre la Biología y su Enseñanza. ISSN 2027-1034

Número Extraordinario. p.p. 317-325

Memorias del Primer encuentro ambiental Universidad, ambiente y sustentabilidad: experiencias y prácticas.

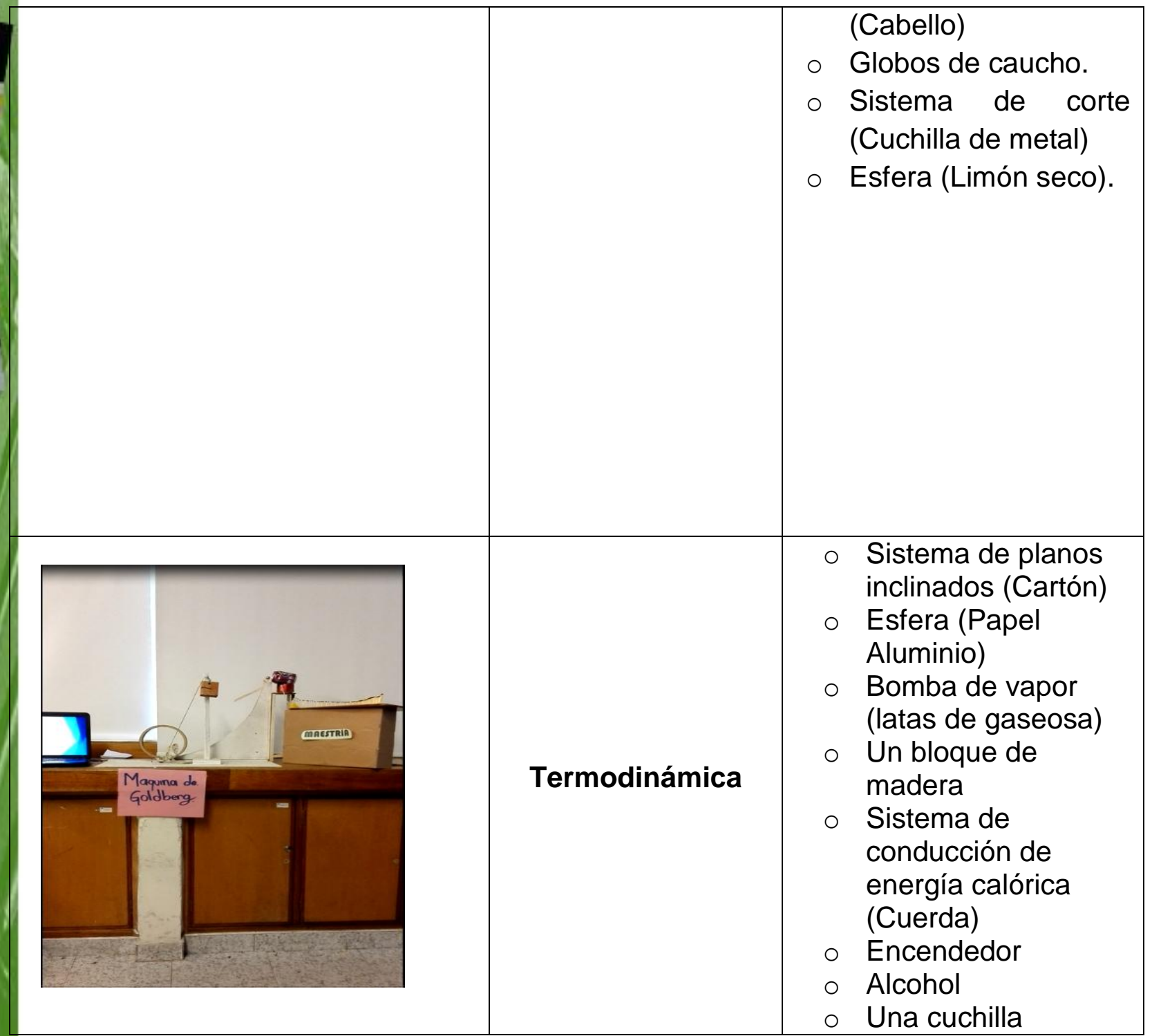


Bio-grafía. Escritos sobre la Biología y su Enseñanza. ISSN 2027-1034

Número Extraordinario. p.p. 317-325

Memorias del Primer encuentro ambiental Universidad, ambiente y sustentabilidad: experiencias y prácticas.
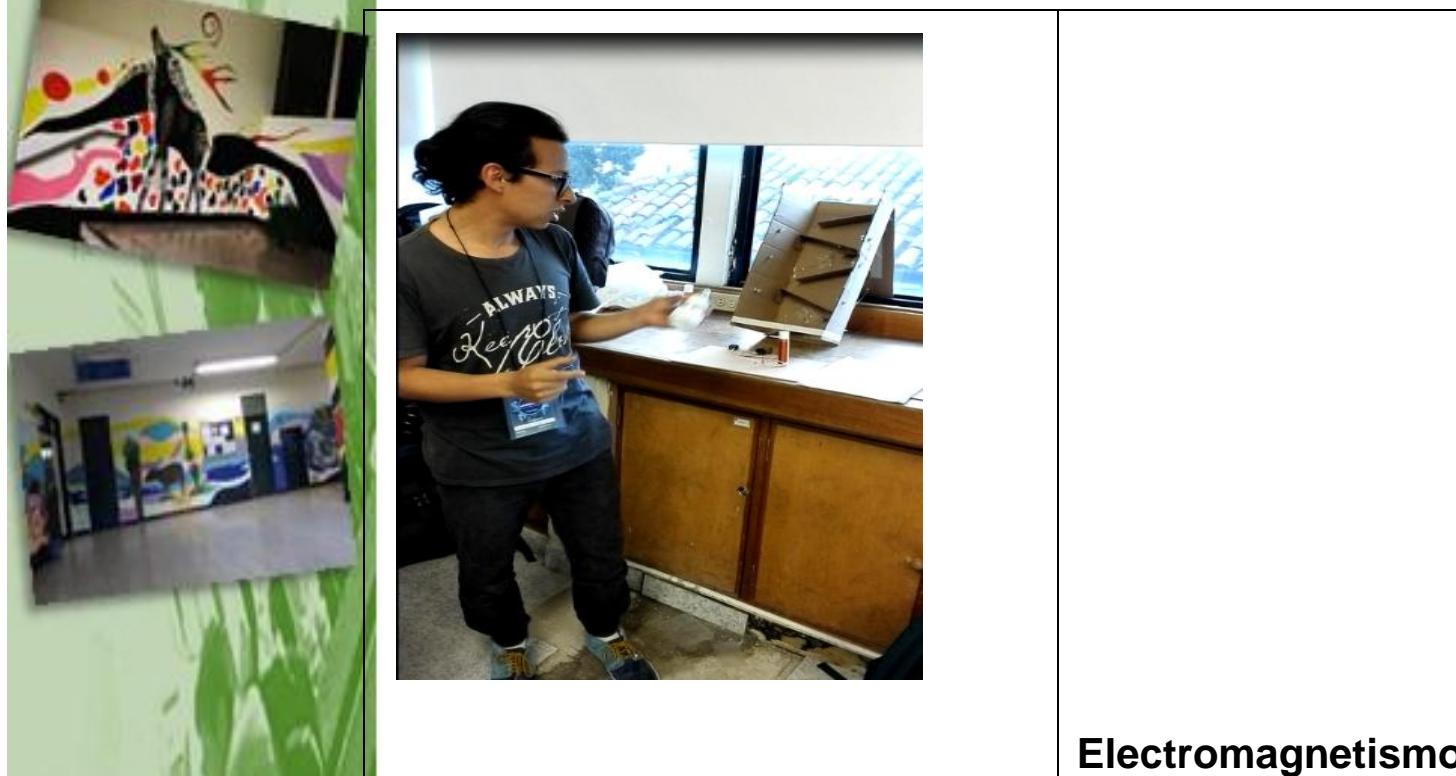

- Sistema de planos inclinados (Cartón)

- Circuito en serie (Bombillas y cable)

- Circuito en paralelo (Bombillas y cable)

- Fuente (Pilas Recargadas)

- Bobina de Tesla (Tubo de hilo y cobre)

- Cuerda

- Fuente de luz (Bombillo Ahorrador fundido)

- Placas de electrones (Papel aluminio)

- Sistema en cadena (fichas de dominó Hechas den cartón)

- Tierra y hojas seca

DESARROLLO METODOLÓGICO

- Momento 1

Se propone a los asistentes construir una máquina de Goldberg con una serie de materiales reutilizados, que cumpla una función específica que indica el tallerista. Para ello se da un tiempo de 10 minutos. 
Bio-grafía. Escritos sobre la Biología y su Enseñanza. ISSN 2027-1034

Número Extraordinario. p.p. 317-325

\begin{abstract}
Memorias del Primer encuentro ambiental Universidad, ambiente y
\end{abstract} sustentabilidad: experiencias y prácticas.

\title{
- Momento 2
}

- Pasado este espacio, se les entrega la guía paso a paso para la construcción y se muestran las diferentes fenomenologías implícitas en cada una de las máquinas.

\section{- Momento 3}

Para finalizar se invita a cambiar alguno de los materiales de la maquina por otro que cumpla la misma función asumiendo que este se dañó, condicionando este cambio a elementos que se encuentren en la basura.

\section{REFLEXIONES}

El papel del maestro es por tanto determinante: en la creación de estrategias que ayuden a que los estudiantes entiendan de una manera más interesante los diferentes temas correspondientes al aprendizaje de la física ya que los métodos utilizados en la actualidad son precarios y de poco interés. En este sentido, toma relevancia la máquina de Goldberg como estrategia de enseñanza de la física en sus diferentes temas, ya que su construcción es sustentable ya que por un lado se apuesta a proteger el entorno natural que nos rodea; y por otro, lo que se hace es lograr un mejor entendimiento por parte de los estudiantes.

Teniendo en cuenta que para nosotros "sustentabilidad" está ligado al uso adecuado de materiales reciclables esta propuesta debía responder de igual manera del uso estos elementos partiendo del hecho de que la 
Bio-grafía. Escritos sobre la Biología y su Enseñanza. ISSN 2027-1034

Número Extraordinario. p.p. 317-325

Memorias del Primer encuentro ambiental Universidad, ambiente y sustentabilidad: experiencias y prácticas.

realización del mismo debía suplir las necesidades de manera inmediata es decir si algún material para la construcción de la misma se dañaba o por alguna razón llegaba a faltar estos se pudieran encontrar fácilmente sin tener que agotar recursos ni generar mayor costo.

Es importante resaltar que los asistentes manifestaron de forma constante su interés en la construcción de cada una de las maquinas. Su admiración aumento al ver toda la fenomenología que se podía explicar desde estas máquinas y por supuesto la facilidad de construcción.

En el último momento del taller, gran porcentaje de los asistentes lograron cambiar un material por algún elemento encontrado en la basura, garantizando que cumplía la misma función.

\section{REFERENCIAS}

- Crespo, M. A. (2003). Concepciones del aprendizaje y la enseñanza: las nuevas propuestas educativas. Enseñar Ciencias en Secundaria. Concepciones del aprendizaje y la enseñanza: las nuevas propuestas educativas, (pág. 16). Bilbao.

- Gualtero Y. (2011). Construcción De Una Máquina De Goldberg Para Potenciar La Observación Y La Descripción De Estudiantes De Grado Sexto. 5o Congreso Nacional De Enseñanza De La Física. Bogotá, Colombia.

- Leiva J. (2010) Maquinas De Rube Goldberg Como Experimento Motivador En La Primera Etapa Del Estudio De La Física En La Escuela Secundaria. Segundo encuentro de enseñanza de las ciencias exactas y Naturales. Risaralda, Colombia. 